\title{
Elder abuse
}

\author{
Mark Bradley
}

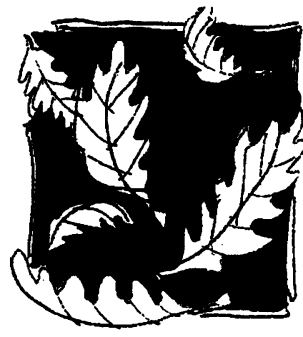

This is the eighth in a series of 14 articles edited by Eileen Burns, Neil Penn, and Graham Mulley

\section{Department of}

Geriatrics/General

Medicine, Seacroft

Hospital, Leeds LS14 6UH

Mark Bradley, senior registrar

BMF 1996;313:548-50
Elder abuse takes many forms and occurs in a variety of settings; it is both under-recognised and under-reported. Despite a lack of statutory guidelines or legislation, effective management is possible. More could be done to recognise abuse, and healthcare workers need to be vigilant, paying attention to both the circumstances in which abuse occurs and its warning signs.

Elder abuse may be physical, sexual, psychological, or financial. It may be intentional, unintentional, or the result of neglect. It causes harm to the older person either temporarily or over a period of time. Abuse occurs in many forms and a variety of settings. The often quoted stereotype of a highly dependent white woman over the age of 75 who is being physically abused by her son or daughter is only a small aspect of this problem.

The scale of the problem is not known as there is no accepted way of recording cases. Attention is increasingly being focused on elder abuse, largely because of the influence of the Community Care Act. Many cases, however, go unreported.

\section{Background}

There are many reasons why older people are abused. The most common include deteriorating family relationships, caregivers who have been abused themselves, social isolation, psychopathology of the abuser, and imbalance of power between abused and abuser. Caring for a sick, dependent elderly person is a challenge for even the most capable person. When caregivers to older people have little support from within the community they may suffer intolerable strain and this may lead to elder abuse. Disturbed sleep, difficult behaviour, and faecal incontinence often result in severe strain on the caregiver and may set the scene for abuse. Many caregivers express feelings of frustration, despair, and worry and of not being cared for themselves. They often feel that the situation is beyond their control. Difficult situations are often compounded by strained family relationships where, for instance, a son or daughter feels a duty to care for a parent of whom they have never been particularly fond or who has treated them badly in the past. The abuser, of course, may be a spouse rather than a younger member of the family. The excessive personal use of alcohol or tranquillising drugs by caregivers can have a disinhibiting effect, which may lead to emotions being translated into physical actions.

Physical abuse is the most commonly encountered form of elder abuse as it is the most easily recognised. Financial abuse, neglect, and sexual abuse are probably both under-recognised and under-reported. Psychological abuse in the form of aggression, humiliation, and intimidation is the most difficult to identify and quantify.

\section{Intervention}

Intervention is complicated and should always be interdisciplinary. There is no correct way of managing elder abuse. It is seldom appropriate for only one person or agency to tackle the problem. Effective intervention will probably involve local authority social services, the health authority, police, and private and voluntary agencies. These agencies should have policies and guidelines for dealing with suspected cases of elder abuse, along with support and training, but often there is no clear framework within which to work. In Britain there is no formalised procedure for dealing with elder abuse, unlike much of the United States, where specific legislation and protocols exist.

A sequence of identification, assessment, and action is usually followed.

Identification is usually through the warning signs given in the box. Warning signs could be spotted by anyone, professional or otherwise, caring for an older person.

Assessment should be done by an interdisciplinary team, which should assess both the caregiver and the patient, focusing on the suspected abuse and its likely cause. A more extensive care planning meeting may be required for complex cases.

Action will result in provision of a care package designed to deal specifically with the situation, ideally allowing the abused person to remain in their own home.

All cases of proved or suspected abuse should be kept under regular review.

Clearly the final care package will vary from case to case but is likely to include some of the following: health information and support, respite care, day care, home

\section{Warning signs \\ Background of abuse}

- Poor family relationships

- History of family violence

- Low income, perhaps with inadequate housing

- Caregivers who are emotionally, physically, and socially isolated

- Lack of privacy for caregivers

- Frequent calls to local agencies

- History of alcohol or drug abuse or mental illness in caregivers

Suspicious circumstances

- Unexplained falls, burns, and fractures

- Bruises in unusual places, such as the inside of the thigh; pinchmarks on the arms

- Inappropriate administration of medication by caregivers

- Provision of inappropriate clothing

- Being left in wet clothing

Signs of financial abuse

- Unexpected inability to pay bills

- Disparity between assets and living conditions

Signs of sexual abuse

- Overt sexual behaviour

- Torn or stained underclothes

- Genital infection and irritation

- "Love" bites

- Bruising and lacerations in the rectovaginal area 
care including nursing, provision of aids and appliances, continence advice, financial advice, advocacy, legal or police intervention, rehousing, and institutional care. Removal of an older person from their home should be seen as a last resort and should not be done without their consent. Support services that are provided should aim to deal with specific problems and should not simply be offered in an attempt "to do something." It should be remembered that most cases of abuse are due to caregiver stress and that intervention will often need to be aimed at helping caregivers to overcome the problems that they themselves are facing. Most caregivers would wish to care in a loving and sensitive way.

\section{Legislation}

Britain has no clear legal framework designed to deal specifically with elder abuse, but there is however some legislation that may be used in certain circumstances. Criminal legislation is seldom useful as the victims of abuse are often afraid and unable to give sufficient evidence to secure conviction in a court. The victim often denies the abuse.

NATIONAL ASSISTANCE ACT

Section 47 of the National Assistance Act 1948 allows a local authority with the certificate of a community physician to apply to a magistrate for removal of the elderly person from their home to a place of safety if the person concerned is suffering from a grave chronic disease or, being aged, infirm, or incapacitated, is living in insanitary conditions; the person is unable to give himself or herself proper care and attention; or the person's removal from home is necessary in their best interests or for preventing injury or serious nuisance to other people. A 1951 amendment allows for the removal without delay of a person for up to three weeks on the application of the community physician supported by a second medical opinion.

\section{COMMUNTTY CARE ACT}

Section 47 of the Community Care Act 1990 requires local authorities to carry out assessments of need where people appear to them to be in need of services.

\section{MENTAL HEALTH ACT}

Under the Mental Health Act 1983 the local authority or an individual may be appointed guardian to a person who is mentally ill. This lasts for six months and there is a right of appeal. Section 115 allows an approved social worker to enter and inspect premises in

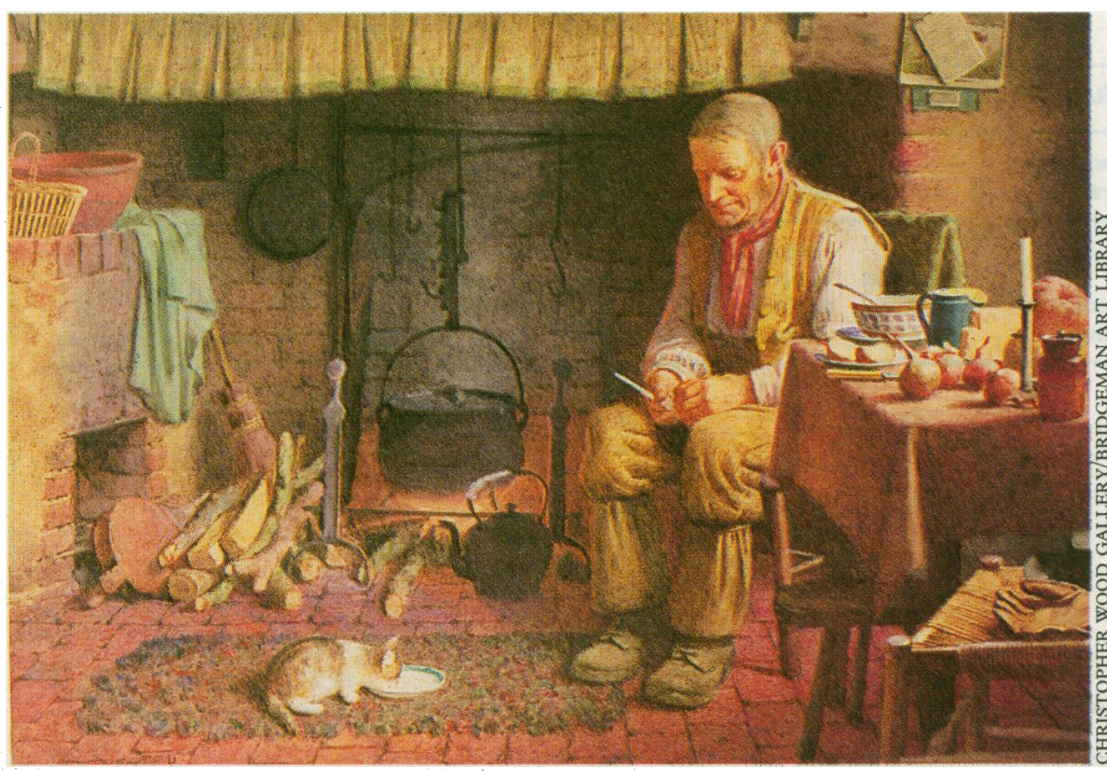

"By the fireside" by Henry Spemon Tozer (f 1892)

\section{The case of $\mathrm{Mr} C$}

$\mathrm{Mr} \mathrm{C}$, a retired miner living at home, is admitted to hospital because of deteriorating mobility and falls. After rehabilitation and treatment for pseudogout and gait apraxia he returns home with increased support from social services. Unfortunately he is readmitted two weeks later with further falls. $\mathrm{He}$ feels that he can no longer manage at home and asks the hospital social worker about going into residential care. His son has been "looking after" his financial affairs, collecting his state and occupational pensions and using them to pay the bills. $\mathrm{Mr} \mathrm{C}$ has little idea what happens to the rest of his money and cannot understand why his son refuses to cooperate with the social services' financial assessment and why he never visits him in hospital.

\section{The case of Mrs D}

Mrs $\mathrm{D}$ lives alone in rented accommodation. Despite a previous stroke, she is reasonably independent in her flat, relying on her family only to collect her pension and to do some shopping. Over a short period of time she becomes increasingly unwell and relies more heavily on her family, but after successful inpatient treatment for a chest infection she returns to her former largely independent self. After a successful home visit she is looking forward to returning to her flat. Over the next few days she becomes more withdrawn, and then suddenly announces that she has decided that she should "go into a home." Subsequent questioning reveals that family members have visited and made it clear that they believe she should not return home; they have threatened that unless she goes "into a home" they will have nothing more to do with her.

which a mentally disordered patient is living if he or she has cause to believe that the patient is not under proper care. Section 127(2) provides that it is an offence for an individual to wilfully neglect a mentally ill person in his or her guardianship. Section 135 allows for a person to be removed to a place of safety for up to 72 hours.

\section{The case of Mrs E}

Mrs E, an elderly Asian woman, lives with her son and his children. She sleeps downstairs, is mobile only with a Zimmer frame, and is occasionally incontinent. She has had a fractured femur and also a fractured humerus. She is admitted to hospital with a painful knee and immobility. Radiographs reveal a fracture of the proximal tibia. She tells an Asian hospital worker that her granddaughter shouts at her when she is incontinent and has kicked her. She does not want to return home. When seen later by an Asian social worker she denies the earlier claims, saying she has slipped. It becomes clear, however, that most of her care at home is provided not by her son and his wife but by the young teenage granddaughter. She continues to deny any further abuse and asks to return home. The family declines all offers of any further help and denies that Mrs $\mathrm{E}$ has been kicked. Her son feels that it is his duty to look after his mother. Mrs $\mathrm{E}$ is discharged home to be monitored by social services, her general practitioner, and the district nurse. 
The Elder Abuse Response Line-0181 679 7074-takes calls from older people, carers, and professionals concerned about elder abuse. It is available Monday and Friday $2 \mathrm{pm}$ to $7.30 \mathrm{pm}$ and Tuesday to Thursday $2 \mathrm{pm}$ to $4.30 \mathrm{pm}$ and is run by Action on Elder Abuse.

COURT OF PROTECTION

The Court of Protection has jurisdiction when a person is incapable by reason of mental disorder of managing and administering his or her property and affairs. The court has wide powers relating to property and affairs but not to matters relating directly to a person's care. A receiver is usually appointed; this is often a relative but it can be anyone suitable. The receiver is not allowed to dispose of assets.

\section{POWER OF ATTORNEY}

Power of attorney allows a person to give authority, for financial matters, to someone else to act on his or her bohalf. Enduring power of attorney is initiated while the person is of sound mind and continues when he or she becomes mentally incapable.

\section{Suggested reading}

Age Concern, British Geriatrics Society, Carers National Association, Help the Aged, Police Federation. Abuse of elderly people. Guidelines for action. London: Age Concern England, 1990.

Department of Health, Social Services Inspectorate. No longer afraid. The safeguard of older people in domestic settings. London: HMSO, 1993.

Social Services Inspectorate. Confronting elder abuse. London: HMSO, 1992.

\section{Corrections}

Grand Rounds-Hammersmith Hospital: Tuberculous enteritis

An editorial error led to authorship of this paper being attributed to the wrong person on the front cover (27 July, pp 215-7). The author is Farah B Ahmed [not S D Taylor Robinson, who is the series editor].

Trials to assess equivalence: the importance of rigorous methods

We regret that an editorial error occurred in this article by Jones et al (6 July, p 36). In the appendix two of the formulas for power calculations had brackets in the wrong places and two had a -1 wrongly inserted. The power calculations for normally distributed data should have appeared as: Two sided case

$$
\text { Power }=2 \Phi\left(\frac{\Delta}{\sqrt{s^{2}\left(\frac{2}{n}\right)}}-z_{(1-\alpha)}\right)-1
$$

One sided case

$$
\text { Power }=\Phi\left(\frac{\Delta}{\sqrt{s^{2}\left(\frac{2}{n}\right)}}-z_{(1-\alpha)}\right)
$$

The power calculation for binary data, one sided case, should have appeared as:

$$
\text { Power }=\Phi\left(\frac{\Delta}{\sqrt{p(100-p)\left(\frac{2}{n}\right)}}-z_{(1-\alpha)}\right)
$$

In addition, in the boxed example on $p 37$ the Greek delta symbol ( $\delta$ ) should have appeared as a Greek sigma to give the phrase: the prior estimate of $\sigma^{2}$.

\section{$B M U$ audit: time to decisions by publication}

We aim to make a decision on publication within eight weeks (56 days); to reject papers that are unsuitable for external peer review within two weeks (14 days) and to publish a paper within eight weeks of acceptance.

Between 1 January and 30 June this year we made a decision within 56 days for $81 \%$ of all papers submitted $(1362 / 1686)$ and for $43 \%$ of those accepted (66/152). We accepted $59 \%$ within 66 days, and the mean time to accept a paper was 59 days. We met our target of rejecting papers without peer review within 14 days for $30 \%$ of papers (313/1044); $65 \%$ were rejected within 24 days, and the average time to reject such papers was 24 days. We published $19 \%$ papers within eight weeks of acceptance, $35 \%$ within 10 weeks, and $53 \%$ within 12 weeks. A comparison with previous audits is shown in

\begin{tabular}{|c|c|c|c|c|c|c|c|c|c|}
\hline \multirow[b]{2}{*}{ Audit } & \multicolumn{2}{|c|}{$\begin{array}{l}\text { Decision within } \\
56 \text { days }\end{array}$} & \multicolumn{2}{|c|}{ Accepted papers } & \multicolumn{2}{|c|}{$\begin{array}{l}\text { Rejected papers } \\
\text { (no peer roview) }\end{array}$} & \multicolumn{3}{|c|}{$\begin{array}{l}\text { Publication after acceptance } \\
\text { within: }\end{array}$} \\
\hline & $\begin{array}{c}\text { All } \\
\text { papers }\end{array}$ & $\begin{array}{l}\text { Accepted } \\
\text { papers }\end{array}$ & $\begin{array}{c}\text { Decision } \\
\text { within } \\
66 \text { days }\end{array}$ & $\begin{array}{l}\text { Mean } \\
\text { time to } \\
\text { declision } \\
\text { (days) }\end{array}$ & $\begin{array}{l}\text { Decision } \\
\text { within } \\
24 \text { days }\end{array}$ & $\begin{array}{l}\text { Mean } \\
\text { time to } \\
\text { decision } \\
\text { (days) }\end{array}$ & $\begin{array}{c}8 \\
\text { weoks }\end{array}$ & $\begin{array}{c}10 \\
\text { weeks }\end{array}$ & $\begin{array}{c}12 \\
\text { weoks }\end{array}$ \\
\hline \multicolumn{10}{|l|}{ 1993: } \\
\hline Jan-June & 88 & 73 & 85 & 41 & 76 & 19 & 38 & 72 & 95 \\
\hline July-Dec & 86 & 62 & 75 & 50 & 84 & 18 & 27 & 66 & 85 \\
\hline \multicolumn{10}{|l|}{ 1994: } \\
\hline Jan-June & 88 & 64 & 76 & 48 & 84 & 18 & 13 & 24 & 57 \\
\hline $\begin{array}{l}\text { July-Dec } \\
\text { 1995: }\end{array}$ & 83 & 64 & 73 & 51 & 73 & 21 & 40 & 67 & 87 \\
\hline Jan-June & 72 & 41 & 53 & 69 & 56 & 26 & 38 & 60 & 76 \\
\hline July-Dec & 73 & 34 & 43 & 81 & 65 & 22 & 32 & 50 & 73 \\
\hline \multicolumn{10}{|l|}{ 1996: } \\
\hline Jan-June & 81 & 43 & 59 & 59 & 65 & 24 & 19 & 35 & 53 \\
\hline
\end{tabular}
the table.

Results of BMJ audits. Values are percentages unless stated otherwise 